Check for updates

Cite this: RSC Adv., 2017, 7, 47983

\title{
A new two-mode fluorescence signal amplification strategy for protease activity assay based on graphene oxide
}

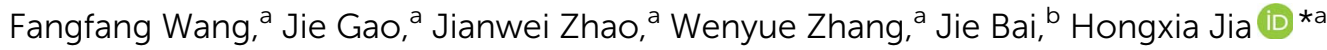
and Yucong Wang*a

A graphene oxide (GO)-based two-mode fluorescence signal amplification assay of protease activity has been established. GO can adsorb the FITC-labeled substrate peptide and quench the fluorescence of FITC. In the presence of the target protein, carboxypeptidase Y (CPY), the FITC-labeled substrate peptide is hydrolyzed by CPY, leading to the turn-on of fluorescence. The fluorescence intensity increases significantly after the hydrolysis. More interestingly, it is even much higher than the fluorescence intensity of the added FITC-labeled substrate peptides. It is deduced that the extraordinary growing of fluorescence intensity is attributed to the hydrolysis also. The strong quenching efficiency of GO significantly improved the signal-to-noise ratio (SNR) of the proposed method for protease analysis. By combining the GO-based fluorescence turn-on with the fluorescence signal amplification induced by hydrolysis, the proposed method obtained higher sensitivity and specificity for CPY activity detection. The detection limit for CPY activity assay is estimated to be $1.0 \times 10^{-5} \mathrm{U} \mathrm{L}^{-1}$. The other proteins, proteases and a complicated matrix cannot disturb the assay of CPY activity.
\end{abstract}

Received 24th July 2017

Accepted 30th September 2017

DOI: 10.1039/c7ra08166a

rsc.li/rsc-advances antibody immobilization, fluorophore labeling and washing again and again. In recent years, peptide-based protease biosensors have attracted more and more attention in the assay of proteases. ${ }^{4}$ The protease biosensors are constructed based on hydrolysis of the substrate peptide by the target protease. Some materials such as nanoparticles, electrochemical materials, fluorescent dyes and so on are chosen as signal markers to conjugate to the substrate peptide firstly. ${ }^{5}$ The target protease can accurately and efficiently hydrolyze its corresponding substrate peptide sequence and the hydrolysis information can be converted into measurable signal through the status change of signal marker. Up to now, fluorescence resonance energy transfer (FRET)-based fluorescence protease sensors is one of the most popular approaches for protease activity monitoring. ${ }^{6}$ In the FRET-based system, donor-acceptor pair is usually attached at the opposite ends of substrate peptide. In presence of target protease, the substrate peptide is hydrolyzed and the fluorescent molecule is released, generating an increase of fluorescence intensity. However, these FRET-based sensors often need double labels, such as fluorescence group and quenching group, which increases the testing cost. Furthermore, the detection sensitivity are particularly affected by the quenching efficiency.

Graphene oxide (GO) is water-soluble derivative of graphene and has been applied as an energy acceptor in the FRET-based protease activity assay due to its super quenching efficiency. ${ }^{7}$ GO is usually fixed on one of terminals of peptide by specific interaction between biotin and streptavidin (STV) or covalent 
conjugation. The formation of linkage requires complicated and time-consuming modification, activation and conversion processes. ${ }^{8}$ It's worth mentioning that GO has another unique property that is super adsorption capacity. ${ }^{9}$ Compared with the complexed connection, the adsorption is more simpler, faster and time saving. Many fluorescence analysis protocols based on the super adsorption property of GO have been widely applied for the detection of various biomolecules. ${ }^{10}$

Carboxypeptidase Y (CPY) is a kind of exopeptidase with nonspecifically hydrolyzing polypeptide chains at the Cterminal (carboxyl-terminal) of the peptide or protein. CPY is a metal ion-independent enzyme and thus it is not inactivated by chelating agents such as EDTA. Moreover, it is highly stable to heat, $\mathrm{pH}$, and denaturing agents. ${ }^{11}$ Due to these unique properties, CPY has been readily available for use in C-terminal sequencing of protein ${ }^{12}$ and hydrolyzing peptide for the kinase assays. ${ }^{13}$ Determination of CPY activity is imperative for gaining a better understanding of the functions of these biomolecules. Herein, we take CPY as the model protease and develop a twomode fluorescence signal amplification strategy for detection of protease activity based on GO.

In this work, fluorophore-labeled substrate peptide is adsorbed onto the surface of GO by electrostatic and $\pi-\pi$ interaction. ${ }^{\mathbf{1 4}}$ The FRET from fluorophore to GO leads to fluorescence quenching. In the presence of CPY, the substrate peptide is hydrolyzed by CPY and thus the fluorescence resonance energy can not transfer from fluorophore to GO, resulting in the turn-on of fluorescence. Meanwhile, we find a very interesting phenomenon that the fluorescence intensity grows dramatically after hydrolysis as the increase of CPY concentration, and even with excess fluorophore-labeled substrate peptides. We deduce that the hydrolysis makes the fluorophores pull away from the influence of amino acid residues of substrate peptides. Therefore, the fluorescent efficiency of fluorophore increases after the hydrolysis and the fluorescence intensity grows dramatically, simultaneously. By integrating the GObased fluorescence turn-on mode and the surprising fluorescence growth induced by peptide hydrolysis, a two-mode fluorescence signal amplification strategy for sensitive detection of target protease activity is proposed.

\section{Results and discussion}

\section{The principle of the proposed assay for protein activity assay}

The assay strategy of GO-based two-mode fluorescence signal amplification assay for CPY activity is illustrated in Fig. 1. A fluorescein-labeled peptide (FITC-TTYADFIASGRTGRRNAIHD, FITC-PEP20) is used as the special substrate peptide for CPY. As shown in the Fig. 1, in the absence of CPY, the FITC-PEP20 is adsorbed onto the surface of GO by the electrostatic and $\pi-\pi$ stacking interaction. The adsorption makes FITC molecule and GO close enough to cause FRET from FITC molecule to GO and further efficient fluorescence quenching. In contrast, in the presence of CPY, the FITC-PEP20 is hydrolyzed by CPY from the C-terminal, generating many free amino acid residues. Therefore, the FITC molecule gets away from the GO after hydrolysis due to the weak binding between them. The FITC molecules are

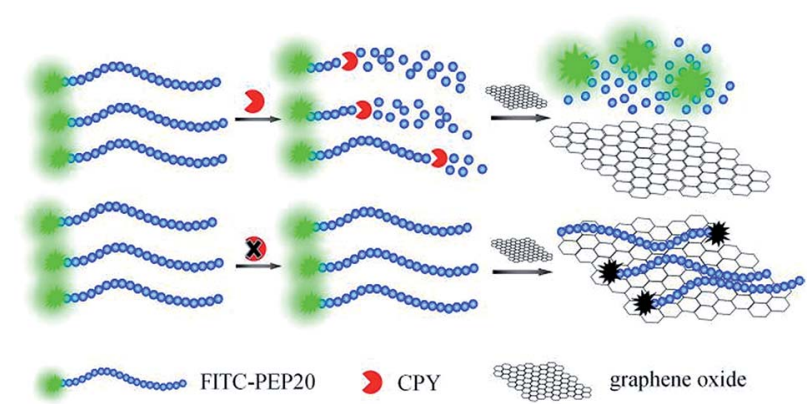

Fig. 1 Schematic illustration of GO-based two-mode fluorescence signal amplification assay of CPY.

released to solution, inducing the fluorescence recovery. The GO-based fluorescence turn-on mode induced by CPY is formed. As shown in the Fig. 2A, the FITC-PEP20 exhibits a higher fluorescence signal (Fig. 2A, blue line). It is almost completely quenched upon the addition of GO (Fig. 2A, black line). When the added FITC-PEP20 is pre-treated with a lower concentration of CPY and then mixed with GO, the fluorescence signal gets partial restoration (Fig. 2A, red line). More intriguingly, when a larger concentration of CPY is used (Fig. 2A, green line), much higher fluorescence signal is observed in comparison to the added FITC-PEP20 alone. To confirm the root cause of the extraordinary fluorescence growth, the experiments in
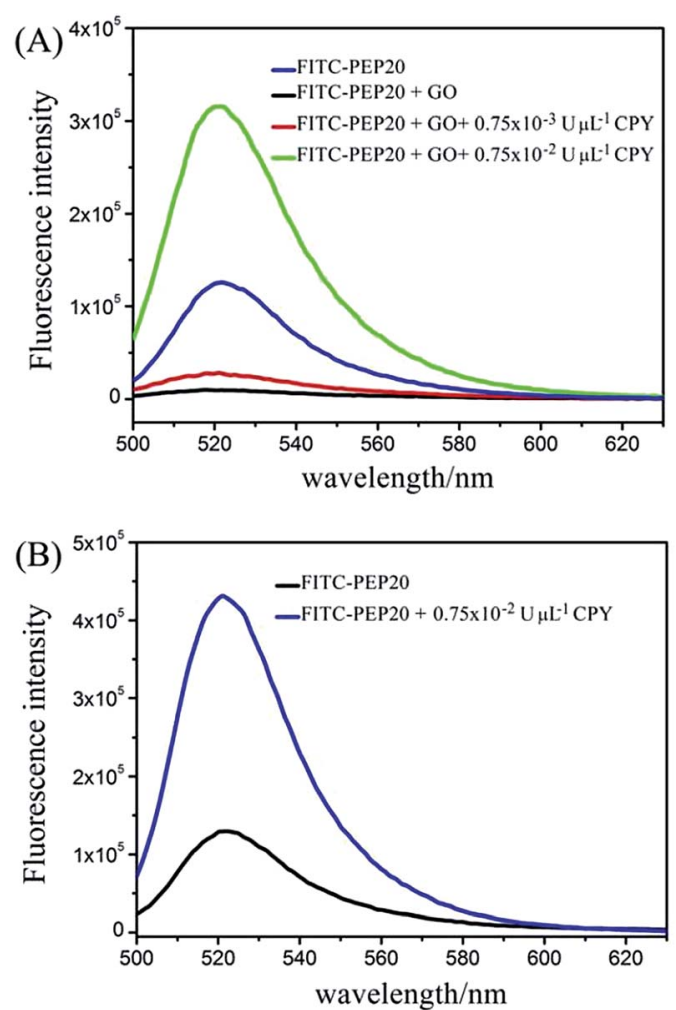

Fig. 2 (A) Fluorescence spectra of the proposed CPY assay based on GO; (B) fluorescence spectra corresponding to the solutions in (A) without GO. Experiment conditions: $100 \mathrm{nmol} \mathrm{L}{ }^{-1}$ FITC-PEP20, $5 \mu \mathrm{gL}^{-1} \mathrm{GO}$. 
contrast without GO are carried out. In the absence of GO, the enhancement of fluorescence induced by CPY can be also observed (Fig. 2B). It is speculated that the fluorescent efficiency of FITC is very sensitive to changes of surrounding environment. When FITC is labeled to the peptide, its fluorescent efficiency is repressed due to the influence of amino acid residues of peptide. After the hydrolysis of FITC-PEP20 by CPY, the surrounding environment which the FITC molecule is in, such as the charge distribution and so on, is changed. The hydrolysis makes the FITC molecule free from the influence of amino acid residues of peptide, and therefore the fluorescent efficiency of FITC molecule increases and the fluorescence signal intensity shows very prominent growth after the hydrolysis. The extraordinary fluorescence growth induced by hydrolysis of peptide forms the fluorescence signal amplification mode. Notably, the strong quenching efficiency of GO significantly improved the signal-to-noise ratio (SNR) of the proposed method for protease assay. With and without GO (Fig. 2A and B), the SNRs of fluorescence in presence of $0.75 \times 10^{-2}{\mathrm{U} \mu \mathrm{L}^{-1}}^{-1}$ CPY are 30 and 4, respectively. The elevated SNR contributes to the higher detection sensitivity. By the combined action of the increase of fluorescence signal induced by hydrolysis and GObased fluorescence turn-on mode, a two-mode fluorescence signal amplification strategy for the determination of CPY is established.

The electrophoresis results of hydrolyzed of FITC-PEP20 by CPY also powerfully demonstrate our inferences. The isoelectric point of PEP20 is 8.34 which is very close with the $\mathrm{pH}$ of the electrophoresis buffer $(\mathrm{pH}=8.0)$. So, the FITC-PEP20 carries very little negative charges in the electrophoresis buffer. As the Fig. 3 shown, in the blank solution without CPY, the FITCPEP20 moves slowly toward the cathode (line 1). In the presence of CPY, the added FITC-PEP20 are hydrolyzed. As the increasing of concentration of CPY, the amount of FITC-PEP20 decreases gradually and the amount of free FITC molecule increases obviously. The corresponding phenomena can be observed in the Fig. 3. The fluorescence bands of the FITCPEP20 gradually become weaker, and even disappeared, while

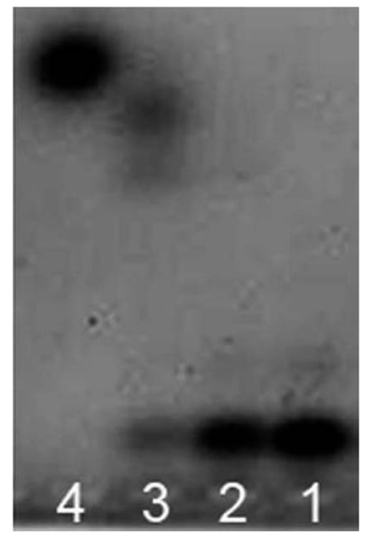

Fig. 3 Electrophoresis results of hydrolysis products of FITC-PEP20 by CPY. Line 1: FITC-PEP20 $10 \mu \mathrm{M}$; line 2: in the presence of $5.0 \times$ $10^{-3} \cup \mu \mathrm{L}^{-1} \mathrm{CPY}$; line 3 : in the presence of $5.0 \times 10^{-2} \mathrm{U} \mu \mathrm{L}^{-1} \mathrm{CPY}$; line 4 : in the presence of $0.5 \cup \mu \mathrm{L}^{-1} \mathrm{CPY}$. The concentration of agarose is $3 \%$. the free FITC molecules enhance progressively as the increasing of CPY dosage from line 1 to line 4 . After the hydrolysis reaction, the free FITC molecules migrate faster to cathode. Furthermore, with the relatively high concentration of CPY, the added FITCPEP20 is hydrolyzed completely and its fluorescence band is disappeared. Instead, a very distinct fluorescence band occurs near the anode (line 4), which is derived from the free FITC molecules. Notably, the fluorescence of free FITC molecules is stronger than that in the added FITC-PEP20 (line 1). It is a very obvious evidence that the fluorescence signal amplification caused by hydrolysis. All of the results displayed above well support our proposed fluorescence amplification mechanism induced by hydrolysis of substrate peptide by CPY.

\section{Optimization of the experimental condition for the CPY activity assay}

To obtain the optimal experimental parameters for the detection of CPY activity, the influences of the hydrolysis time of FITC-PEP2 0 by CPY, the concentration of GO and the quenching time of GO to FITC-PEP20 in this assay are investigated.

To investigate the influence of the concentration of GO on the fluorescence quenching process, various concentrations of GO $\left(0.5-15 \mu \mathrm{g} \mathrm{mL}{ }^{-1}\right)$ are incubated with $100 \mathrm{nM}$ FITC-PEP20, and then the fluorescence spectra of mixtures are recorded. As Fig. 4 shown, the fluorescence intensities decrease quickly as the increasing of concentration of GO. The fluorescence is quenched completely at $5.0 \mu \mathrm{g} \mathrm{mL}^{-1} \mathrm{GO}$. So, $5.0 \mu \mathrm{g} \mathrm{mL} \mathrm{L}^{-1} \mathrm{GO}$ is selected for the detection of CPY in this study.

The kinetics curve of quenching time of GO to FITC-PEP20 is also drawn. As shown as Fig. 5, GO can interact with FITC-PEP20 and quench its fluorescence with $1 \mathrm{~min}$. Extended time does not change the fluorescence intensities. Therefore, the FITC-PEP20 and GO are co-incubated for $1 \mathrm{~min}$ prior to the measurement.

In addition, the influence of hydrolysis time of CPY to FITCPEP20 is investigated in a period of $10 \mathrm{~h}$ after mixing the FITCPEP20 and CPY in Tris-HCl buffer solution. The fluorescence measurements are carried out after incubation of the mixtures and GO for $1 \mathrm{~min}$. As Fig. 6 shows that the blank is composed of FITC-PEP20 and GO, without CPY, generating fluorescence

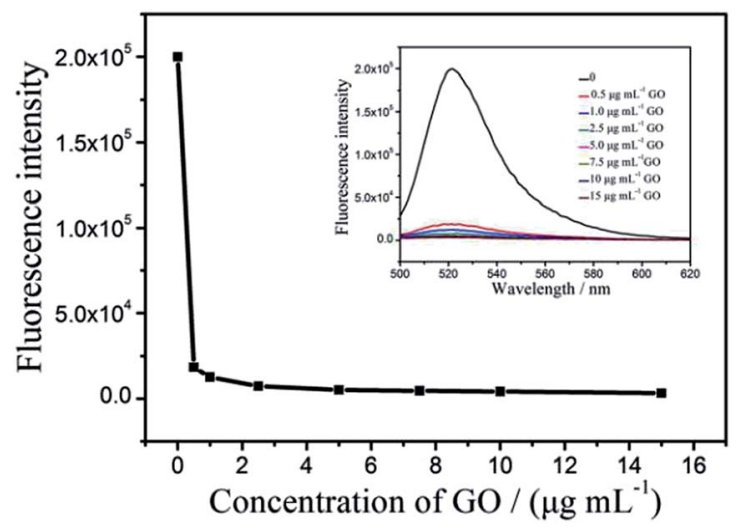

Fig. 4 The influence of the concentration of GO on the fluorescence quenching process. The concentration of FITC-PEP20 is $100 \mathrm{nM}$. 


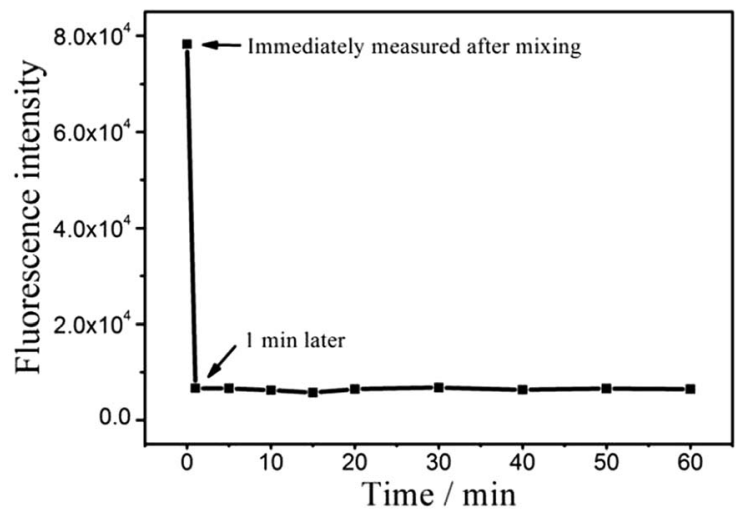

Fig. 5 The influence of the quenching time on the fluorescence of FITCPEP20 after adding GO. FITC-PEP20 is $100 \mathrm{nM}, \mathrm{CPY}$ is $1 \times 10^{-3} \mathrm{U} \mathrm{L} \mathrm{L}^{-1}$ $\mathrm{GO}$ is $5.0 \mu \mathrm{g} \mathrm{mL}^{-1}$. Other conditions are performed according to the experimental procedure described in Experimental section.

quenching. In the presence of CPY, fluorescence signals are recovered gradually as the increasing of the hydrolysis time and reach its peak level at $8 \mathrm{~h}$. So, $8 \mathrm{~h}$ is selected as hydrolysis time of CPY to FITC-PEP20 for the further experiments.

\section{The CPY activity assay}

Under the optimum conditions, the target protease, CPY, is detected quantitatively by using the proposed protease assay. As Fig. 7 shows that the fluorescence signals gradually increase as

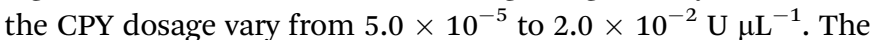
fluorescence intensities at $517 \mathrm{~nm}$ are linearly dependent on the

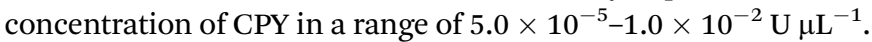
The correlation equation is $I_{\mathrm{F}}=3872.87+3582.53 C_{\mathrm{CPY}}$ $\left(\times 10^{-4} \mathrm{U} \mu \mathrm{L}^{-1}\right)$ with the correlation coefficient of 0.9974 . The detection limit of the target protease, CPY, is evaluated to be

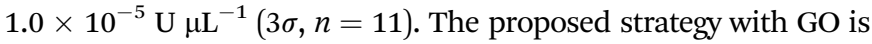
further compared with that without GO. As shown in the Fig. 8, the

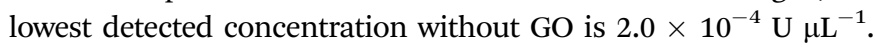
The detection sensitivity of the proposed GO-based assay is one

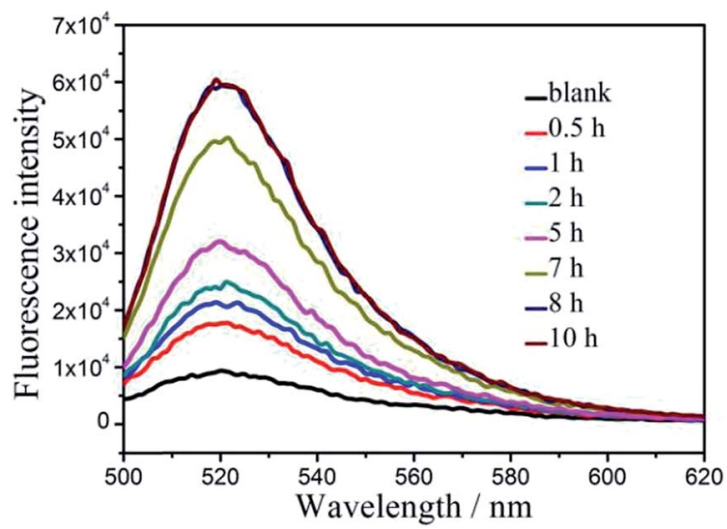

Fig. 6 The influence of the hydrolysis time of CPY to FITC-PEP20 on the fluorescence signal. FITC-PEP20 is $100 \mathrm{nM}, \mathrm{CPY}$ is $1 \times 10^{-3} \mathrm{ULL}^{-1}$, $\mathrm{GO}$ is $5.0 \mu \mathrm{g} \mathrm{mL}^{-1}$. Other conditions are performed according to the experimental procedure described in Experimental section.
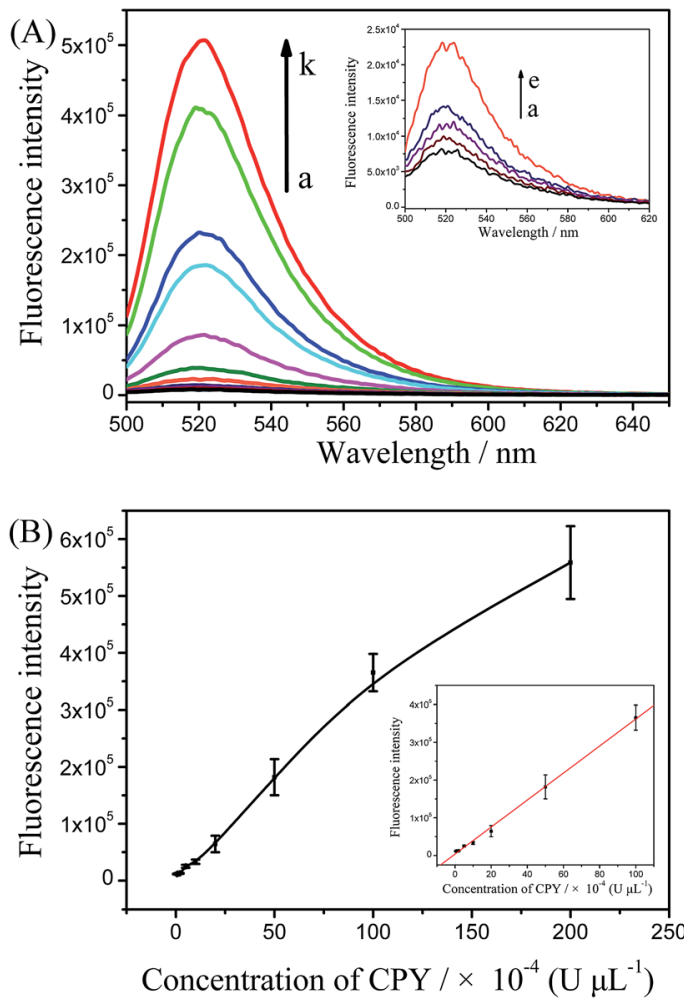

Fig. 7 (A) Fluorescence spectra of the proposed assay system in the presence of different concentrations of CPY. The concentrations of CPY from (a) to $(\mathrm{k})$ is $0,5.0 \times 10^{-5}, 1.0 \times 10^{-4}, 2.0 \times 10^{-4}, 5.0 \times 10^{-4}, 1.0 \times$ $10^{-3}, 2.0 \times 10^{-3}, 4.0 \times 10^{-3}, 5.0 \times 10^{-3}, 1.0 \times 10^{-2}$ and $2.0 \times 10^{-2} \mathrm{U}$ $\mu \mathrm{L}^{-1}$, respectively. The insert shows an enlargement of the results obtained with $C P Y$ concentration between 0 and $5.0 \times 10^{-4} \cup \mu L^{-1}$; (B) the relationship between the fluorescence intensity at $517 \mathrm{~nm}$ and CPY concentrations. Other conditions are performed according to the experimental procedure described in Experimental section.

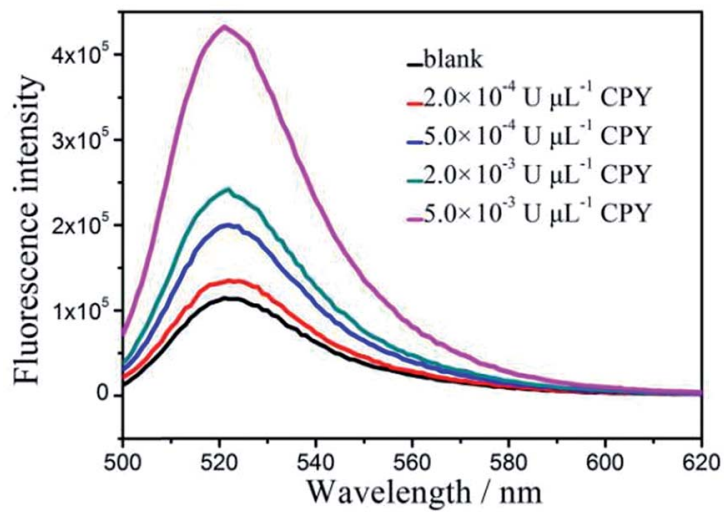

Fig. 8 Fluorescence spectra of the CPY assay system without GO in the presence of different concentrations of CPY. FITC-PEP2O is $100 \mathrm{nM}$. The blank is without CPY.

order of magnitude higher than that without GO. This detection limit is comparable or better than some other FRET-based methods for protease activity detection (shown in Table 1). 
Table 1 Comparation of various FRET-based methods for protease activity assay

\begin{tabular}{lll}
\hline Target protease & Detection limit & Ref. \\
\hline Caspase-3 & $200 \mathrm{ng} \mathrm{mL} \mathrm{mL}^{-1}$ & $15 a$ \\
Caspase-3 & $1.4 \mathrm{nM}\left(45 \mathrm{ng} \mathrm{mL}^{-1}\right)$ & $15 b$ \\
Thrombin & $11 \mathrm{nM}\left(407 \mathrm{ng} \mathrm{mL}^{-1}\right)$ & $15 c$ \\
Thrombin & $2 \mathrm{nM}\left(74 \mathrm{ng} \mathrm{mL}^{-1}\right)$ & $10 d$ \\
Trypsin & $1 \mathrm{nM}\left(24 \mathrm{ng} \mathrm{mL}^{-1}\right)$ & $15 d$ \\
CPY & $1 \times 10^{-5} \mathrm{U} \mathrm{LL}^{-1}\left(105 \mathrm{ng} \mathrm{mL}^{-1}\right)$ & This work
\end{tabular}

\section{The selectivity of the CPY activity assay}

To evaluate the specificity of the proposed protease assay, the interference of other seven proteins and proteases, including BSA, HSA, IgG, STV, lysozyme, pepsin and glucose oxidase is investigated. Under the optimum conditions, the fluorescence signal produced by CPY can be separated completely from those generated from by the other proteins and proteases. As shown in Fig. 9, only CPY can induce the significant fluorescence recovery. In presence of the interference proteins or proteases, the fluorescence curves are similar with that produced by the blank. The interferences for the detection of CPY by the signals produced by other proteins and proteases are estimated to be below 7\%. And the spiked the complex sample with the addition of CPY

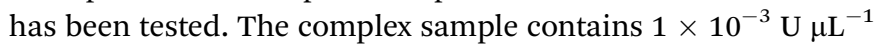
BSA, HSA, IgG, STV, lysozyme, pepsin, glucose oxidase and CPY.

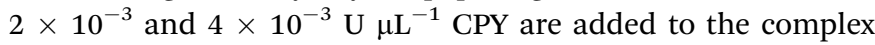
samples, respectively. The average concentrations of CPY determined for three repetitive measurements are $2.72 \times 10^{-3}$

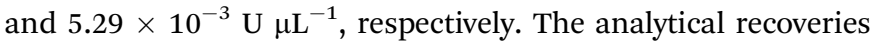
are $87.5 \%$ and $108 \%$. All these results clearly certify that the proposed assay to detect target protease allowed the excellent specificity.

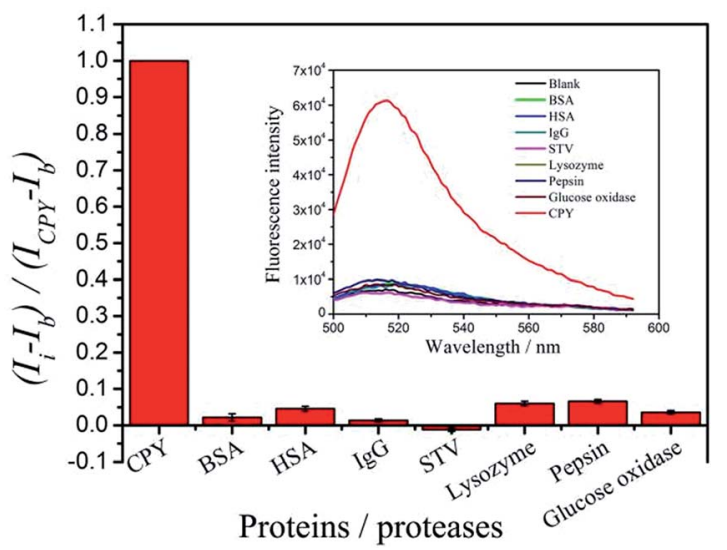

Fig. 9 Selectivity of the CPY assay over other proteins and proteases. The concentrations of other proteins, proteases and CPY are $10.5 \mu \mathrm{g} \mathrm{mL}^{-1}$. $10.5 \mu \mathrm{g} \mathrm{mL}^{-1} \mathrm{CPY}$ is equal to be $2 \times 10^{-3} \mathrm{U} \mu \mathrm{L}^{-1} \mathrm{CPY}$. The CPY is quantified by the modified Lowry protein assay kit with bovine serum albumin as the standard (SK3051, Sangon, Shanghai). Other conditions are performed according to the experimental procedure described in Experimental section.

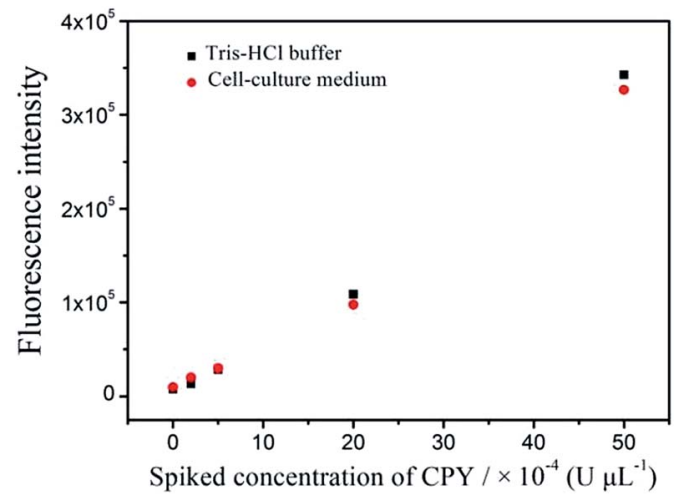

Fig. 10 Fluorescence assay for CPY in the presence of complicated matrix. $100 \mathrm{nM}$ FITC-PEP20, $5.0 \mu \mathrm{g} \mathrm{mL}^{-1} \mathrm{GO}$. Other conditions are performed according to the experimental procedure described in Experimental section.

To validate whether our proposed method could be applied to the real samples with the complicated matrix, the cell-culture medium is used as complicated matrix to do the spiking test. The fluorescence signals produced by the same concentrations of CPY in the complicated systems coincide with that in the Tris-HCl buffer system (Fig. 10). The results show that the proposed method is undisturbed by complicated matrix.

\section{Conclusions}

In summary, we have demonstrated that hydrolysis of peptide can improve the fluorescence efficiency of fluorescein labeled on peptide, inducing the significant increasing of fluorescence intensity. Via the super fluorescence quenching capacity of GO, the proposed protein assay obtained a good SNR. By integrating GO-based fluorescence turn-on and signal amplification induced by hydrolysis of substrate peptide, a new two-mode fluorescence signal amplification strategy is proposed for the sensitive detection of target protease. The detection limit for

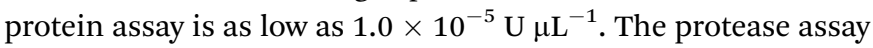
also exhibits a great dynamic range of over 3 orders of magnitude and high specificity to be undisturbed by other proteins, proteases and complicated matrix. This detection strategy is simple, cost-effective and with high selectivity. It can contribute significantly to the applications in the detection of complex biological samples.

\section{Experimental section}

\section{Materials and apparatus}

Carboxypeptidase Y (CPY) and trihydroxy methyl amino methane (Tris) are obtained from Sigma-Aldrich (Shanghai) Trading Co. Ltd. (China). Graphite powder is purchased from Alfa Aesar (Tianjin) Chemical Co. Ltd. (China). The FITC-labeled substrate peptide (FITC-TTYADFIASGRTGRRNAIHD, FITCPEP20) is customized synthesis by GL Biochem (Shanghai) Co. Ltd. All other reagents are analytical reagent grade. Doubledistilled water is used throughout. 
The hydrolysis of peptide by CPY is performed on a CHB-100 isothermal metal bath (Hangzhou Bioer Technology Co. Ltd., China). The fluorescence curves are measured on a Fluorolog 3-211 fluorescence spectrophotometer (Horiba Jobin-Yvon, France).

\section{Synthesis and characterization of graphene oxide}

Graphene Oxide (GO) is prepared according to a modified Hummer's method. ${ }^{16}$ Briefly, $20 \mathrm{~mL}$ of concentrated $\mathrm{H}_{2} \mathrm{SO}_{4}$ is added slowly into a $500 \mathrm{~mL}$ of three necked flask and mixed with $0.5 \mathrm{~g}$ of graphite powder. The mixture is stirred for $2 \mathrm{~h}$ at room temperature. Afterwards, $2.5 \mathrm{~g}$ of $\mathrm{KMnO}_{4}$ is added progressively with stirring and the temperature is kept below $20^{\circ} \mathrm{C}$. And then the mixture is stirred at $35{ }^{\circ} \mathrm{C}$ for $2 \mathrm{~h}$. Successively, keep the temperature of mixture below $50{ }^{\circ} \mathrm{C}$ and $45 \mathrm{~mL}$ double-distilled water is added and the mixture is stirred at room temperature for $3 \mathrm{~h}$. Next, the reaction is terminated by the addition of $112.5 \mathrm{~mL}$ double-distilled water and $5.0 \mathrm{~mL} \mathrm{H}_{2} \mathrm{O}_{2}(30 \%)$ under stirring for $15 \mathrm{~min}$. Following that, the mixture is washed with $1: 10 \mathrm{HCl}$ aqueous solution, and then distilled water for several times. Exfoliation is carried out by sonicate dispersion of GO for $2 \mathrm{~h}$. Finally, the mixture is centrifuged at $6600 \mathrm{rpm}$ for $10 \mathrm{~min}$, and the supernatant is removed and used for further experiments as homogeneous solution of GO.

\section{Procedures for CPY detection based on GO}

To hydrolyze substrate peptide, various concentrations of CPY and $100 \mathrm{nM}$ substrate peptide (FITC-PEP20) are mixed and incubated for $8.0 \mathrm{~h}$ at room temperature in $200 \mu \mathrm{L}$ of Tris-HCl buffer (50 mM, pH 7.5). Afterwards, GO (final concentration of $\sim 5 \mu \mathrm{g} \mathrm{mL}{ }^{-1}$ ) is added to the mixture and incubated for $1 \mathrm{~min}$. Then the fluorescence spectra are measured on an Fluorolog 3-211 fluorescence spectrometer. The excitation wavelength is $480 \mathrm{~nm}$, the emission wavelength is $500-650 \mathrm{~nm}$. The width of excitation and emission slits are both $5 \mathrm{~nm}$.

\section{Procedures for CPY detection without GO}

$100 \mathrm{nM}$ of FITC-PEP20 is incubated with different concentrations of CPY in Tris-HCl (50 mM Tris-HCl, pH 7.5) buffer for $8 \mathrm{~h}$. Then, fluorescence spectra are recorded by Fluorolog 3-211 fluorescence spectrometer.

\section{Procedures for CPY detection in cell-culture medium}

A certain concentration of CPY, $100 \mathrm{nM}$ substrate peptide (FITCPEP20) and $1 \mu \mathrm{L}$ DMEM medium containing $20 \%$ fetal bovine serum are mixed in $200 \mu \mathrm{L}$ of Tris- $\mathrm{HCl}$ buffer $(50 \mathrm{mM}, \mathrm{pH} 7.5)$. The mixture is incubated for $8.0 \mathrm{~h}$ at room temperature in the isothermal metal bath for hydrolysis. Afterwards, GO (final concentration of $\sim 5 \mu \mathrm{g} \mathrm{mL} \mathrm{mL}^{-1}$ ) is added to the mixture and incubated for $1 \mathrm{~min}$. Then, fluorescence spectra are recorded by Fluorolog 3-211 fluorescence spectrometer.

\section{Conflicts of interest}

There are no conflicts of interest to declare.

\section{Acknowledgements}

The project is supported by the National Natural Science Foundation of China (21405032, 21605035); and the Natural Science Foundation of Hebei Province (B2016201052, B2015201130).

\section{Notes and references}

1 X. S. Puente, L. M. Sánchez, C. M. Overall and C. López-Otín, Nat. Rev. Genet., 2003, 4, 544.

2 (a) S. P. M. Lutgens, K. B. J. M. Cleutigens, M. J. A. P. Daemen and S. Heeneman, FASEB J., 2007, 21, 3029; (b) W. B. Luo, Y. F. Wang and G. Reiser, Brain Res. Rev., 2007, 56, 331; (c) U. H. Iloeje, Y. yuan, G. L. Italien, J. Mauskopf, S. D. Holmberg, A. C. Moorman, K. C. Wood and R. D. Moore, HIV Med., 2005, 6, 37; (d) S. Lee, E. J. Cha, K. Park, S. Y. Lee, J. K. Hong, I. C. Sun, S. Y. Kim, K. Choi, I. C. Kwon, K. Kim and C. H. Ahn, Angew. Chem., Int. Ed., 2008, 47, 2804.

3 (a) E. P. Diamandis, G. M. Yousef, A. R. Soosaipillai, L. Grass, A. Porter, S. Little and G. Sotiropoulou, Clin. Biochem., 2000, 33, 369; (b) H. K. Yoon and T. H. Yoo, Analyst, 2013, 138, 7164.

4 Q. T. Liu, J. F. Wang and B. J. Boyd, Talanta, 2015, 136, 114. 5 (a) J. M. Ellard, T. Zollitsch, W. J. Cummins, A. L. Hamilton and M. Bradley, Angew. Chem., Int. Ed., 2002, 41, 3233; (b) J. H. Choi, H. S. Kim, J. W. Choi, J. W. Hong, Y. K. Kim and B. K. Oh, Biosens. Bioelectron., 2013, 49, 415; (c) N. Zhao, Y. Q. He, X. Mao, Y. H. Sun, X. B. Zhang, C. Z. Li, Y. H. Lin and G. D. Liu, Electrochem. Commun., 2010, 12, 471; (d) J. Adjémian, A. Anne, G. Cauet and C. Demaille, Langmuir, 2010, 26, 10347; (e) W. Pham, Y. Choi, R. Weissleder and C. H. Tung, Bioconjugate Chem., 2004, 15, 1403.

6 (a) H. P. Kapprell, A. Maurer, F. Kramer, B. Heinrich, C. Buenning, A. Narvaez, H. Kalbacher and T. Flad, Assay Drug Dev. Technol., 2011, 9, 549; (b) R. Fudala, A. P. Ranjan, A. Mukerjee, J. K. Vishwanatha, Z. Gryczynski, J. Borejdo, P. Sarkar and I. Gryczynski, Curr. Pharm. Biotechnol., 2011, 12, 834; (c) W. E. Kaman, A. G. Hulst, P. T. W. van Alphen, S. Roffel, M. J. van der Schans, T. Merkel, A. van Belkum and F. J. Bikker, Anal. Chem., 2011, 83, 2511.

7 (a) B. Y. Feng, L. J. Guo, L. H. Wang, F. Li, J. X. Lu, J. M. Gao, C. H. Fan and Q. Huang, Anal. Chem., 2013, 85, 7732; (b) C. H. Lu, J. Li, X. J. Qi, X. R. Song, H. H. Yang, X. Chen and G. N. Chen, J. Mater. Chem., 2011, 21, 10915; (c) S. Kim, S. R. Ryoo, H. K. Na, Y. K. Kim, B. S. Choi, Y. Lee, D. E. Kim and D. H. Min, Chem. Commun., 2013, 49, 8241; (d) V. Kotikam, M. Fernmandes and V. A. Kumar, Phys. Chem. Chem. Phys., 2012, 14, 15003.

8 (a) H. B. Wang, Q. Zhang, X. Chu, T. T. Chen, J. Ge and R. Q. Yu, Angew. Chem., Int. Ed., 2011, 50, 7065; (b) J. Li, C. H. Lu, Q. H. Yao, X. L. Zhang, J. J. Liu, H. H. Yang and G. N. Chen, Biosens. Bioelectron., 2011, 26, 3894; (c) E. Q. Song, D. Cheng, Y. Song, M. D. jiang, J. F. Yu and Y. Y. Wang, Biosens. Bioelectron., 2013, 47, 445. 
9 (a) C. H. Lu, H. H. Yang, C. L. Zhu, X. Chen and G. N. Chen, Angew. Chem., Int. Ed., 2009, 48, 4785; (b) H. X. Chang, L. H. Tang, Y. Wang, J. H. Jiang and J. H. Li, Anal. Chem., 2010, 82, 2341; (c) Y. Wang, Z. H. Li, D. H. Hu, C. T. Lin, J. H. Li and Y. H. Lin, J. Am. Chem. Soc., 2010, 132, 9274.

10 (a) S. J. He, B. Song, D. Li, C. F. Zhu, W. P. Qi, Y. Q. Wen, L. H. Wang, S. P. Song, H. P. Fang and C. H. Fan, Adv. Funct. Mater., 2010, 20, 453; (b) H. J. Jang, Y. K. Kim, H. M. Kwon, W. S. Yeo, D. E. Kim and D. H. Min, Angew. Chem., Int. Ed., 2010, 49, 5703; (c) X. G. Liu, X. J. Xing, B. Li, Y. M. Guo, Y. Z. Zhang, Y. Yang and L. F. Zhang, Biosens. Bioelectron., 2016, 81, 460; (d) M. Zhang, B. C. Yin, X. F. Wang and B. C. Ye, Chem. Commun., 2011, 47, 2399; (e) D. B. Zhu, L. Zhang, W. G. Ma, S. Q. Lu and X. B. Xing, Biosens. Bioelectron., 2015, 65, 152.

11 (a) R. Hayashi, Y. Bai and T. Hata, J. Biol. Chem., 1975, 250, 5221; (b) R. W. Kuhn, K. A. Walsh and H. Neurath, Biochemistry, 1974, 13, 3871.
12 D. H. Patterson, G. E. Tarr, F. E. Regnier and S. A. Martin, Anal. Chem., 1995, 67, 3971.

13 (a) J. Zhou, X. H. Xu, W. Liu, X. Liu, Z. Nie, M. Qing, L. H. Nie and S. Z. Yao, Anal. Chem., 2013, 85, 5746; (b) H. S. Yin, X. X. Wang, Y. L. Guo, Y. L. Zhou and S. Y. Ai, Biosens. Bioelectron., 2015, 66, 77.

14 (a) C. Rajesh, C. Majumder, H. Mizuseki and Y. Kawazoe, J. Chem. Phys., 2009, 130, 124911; (b) G. F. Chen, H. Shi, F. F. Ban, Y. Y. Zhang and L. Z. Sun, Microchim. Acta, 2015, 182, 2469.

15 (a) P. M. Shih, T. K. Liu and K. T. Tan, Chem. Commun., 2013, 49, 6212; (b) H. J. Kang, J. H. Kim and S. J. Chung, Biosens. Bioelectron., 2015, 67, 413; (c) M. Wu, E. Petryayeva and W. R. Algar, Anal. Chem., 2014, 86, 11181; (d) D. L. Liao, Y. X. Li, J. Chen and C. Yu, Anal. Chim. Acta, 2013, 784, 72.

16 (a) W. S. Hummers and R. E. Offeman, J. Am. Chem. Soc., 1958, 80, 1339; (b) C. H. Liu, Z. Wang, H. X. Jia and Z. P. Li, Chem. Commun., 2011, 47, 4661. 